\title{
ESTIMAÇÃO DO TEMPO DE TRÂNSITO DAS ÁGUAS NO ESTUÁRIO DO RIO ITAJAÍ-AÇÚ
}

\author{
ZALESKI, A.R. \& C.A.F. SCHETTINI \\ Universidade do vale do Itajaí, Centro de Ciências Tecnológicas, da Terra e do Mar, \\ Laboratório de Oceanografia Física. R. Uruguai, 458, Itajaí, SC, cep 88302.202, tel. 47 \\ 3417720 , fax. 473417715 , \\ a.r.z@ibest.com.br; guto@cttmar.univali.br.
}

\begin{abstract}
RESUMO
O Estuário do rio Itajaí-Açu é um estuário altamente estratificado, e apresenta durante a maior parte do ano uma proeminente cunha salina. Devido a esta característica foi possível aplicar o modelo de caixa, baseado no teorema hidrográfico de Knudsen, para se estimar o balanço salino e o tempo de trânsito das águas fluvial e marinha no estuário. Este modelo possibilita verificar o estado estático das condições de mistura no estuário e não deve ser confundido com as condições médias do estuário. Uma característica positiva deste modelo é o fato dele precisar de um numero pequeno de parâmetros, como perfil de salinidade, volume do estuário e dados de corrente, estes últimos estimados a partir de dados de descarga fluvial. Foram analisados sete dias de dados, compreendendo um ciclo completo de maré (sizígia-quadratura). Dados de velocidade vertical, estimados pelo modelo, mostraram que as condições de maré de sizígia causam um maior grau de mistura. Para confirmar isto foi definido um coeficiente de mistura dado pela razão do conteúdo de água fluvial pelo de água de mistura, o que comprovou tal padrão. Quanto ao tempo de transito, verificou-se que em situações de média descarga, cerca de $215 \mathrm{~m}^{3} \cdot \mathrm{s}^{-1}$, o tempo de trânsito da água marinha foi três vezes maior do que o da água fluvial. Os valores estimados foram de 13.2 horas para a água fluvial e 50.7 horas para água marinha.
\end{abstract}

Palavras-chave: estuário, tempo de trânsito, cunha salina, rio Itajaí-Açu.

\section{TRANSIT TIME IN ITAJAÍ-AÇÚ RIVER ESTUARY}

\begin{abstract}
The Itajaí-Açu estuary is classified as a highly stratified and presents most of the time a salt wedge. Considering this characteristic, it was used a box model, based on Knudsen hidrographic teorem, to estimate the salt balance and the transit time of fluvial and marine waters in this estuary. This model enables to verify the steady state of mixture conditions and should not be confused as the mean conditions of the estuary. A positive characteristic of this model is that it needs a small number of parameters such as salinity profiles, the estuary volume and currents data, being the latter estimated from river discharge. Seven days of data were assessed, comprising a half synodical cycle (spring-neap tide). Vertical velocities data, estimated by the model, showed that spring tide condition causes a more effective mixing. It was stated a ratio of content of fluvial water to the content of mixohaline water, which confirmed the early findings of intensification of mixing during spring tide period. The estimation of the transit time of fluvial and marine water in the estuary for medium discharge condition, $\sim 215 \mathrm{~m}^{3} . \mathrm{s}^{-1}$, were 13.2 and 50.7 hours, respectively. It shows that the marine water spends 3 times more time in the estuary than the fluvial water.
\end{abstract}

Key words: estuary, transit time, box model, salt wedge, Itajaí-Açu river. 


\section{INTRODUÇÃO}

Estuários são corpos de água costeiros restritos com uma livre conexão com o mar aberto, dentro dos quais ocorre a diluição significativa da água do mar pela água doce proveniente da drenagem continental (Cameron \& Pritchard, 1963). Em função da morfologia, do regime de marés e da descarga fluvial, diferentes padrões de mistura podem ocorrer (Dyer, 1997). Em termos gerais, estuários localizados em zonas de micro marés, com um fornecimento constante de água doce, tendem a apresentar-se altamente estratificados. Esta situação implica no escoamento da água fluvial menos densa por sobre a água marinha mais densa, formando uma feição denominada de cunha salina. Nestes ambientes, o principal processo de transporte deve-se a advecção fluvial, com os efeitos da maré incidindo principalmente na mistura vertical.

O estuário do rio Itajaí-açu está localizado no litoral centro-norte do estado de Santa Catarina, entre os municípios de Itajaí e
Navegantes (Figura 1). Este é um estuário altamente estratificado, apresentando durante a maior parte do tempo uma proeminente cunha salina (Schettini et al., 1997). A descarga fluvial pode explicar aproximadamente $70 \%$ da variabilidade da posição da extremidade da cunha do estuário do rio Itajaí-açu (Schettini \& Truccolo, 1999), os demais 30\% podem estar associados à variação devido aos ciclos de maré, ou ainda à oscilações de baixa freqüência no oceano decorrentes de fenômenos meteorológicos. Em condições de baixa descarga fluvial, a cunha salina no estuário do rio Itajaí-Açu pode penetrar até $25 \mathrm{~km}$ a montante da foz, e após períodos prolongados de estiagem, até mais do que $30 \mathrm{~km}$ (Schettini, 2002).

O tempo de trânsito, definido como o tempo necessário para que uma partícula entre e saia de um volume de controle, é um parâmetro de grande importância para avaliar a capacidade de renovação de ambientes costeiros. Na maior parte dos casos, este tempo é estimado basicamente pela entrada da componente fluvial, enquanto que a

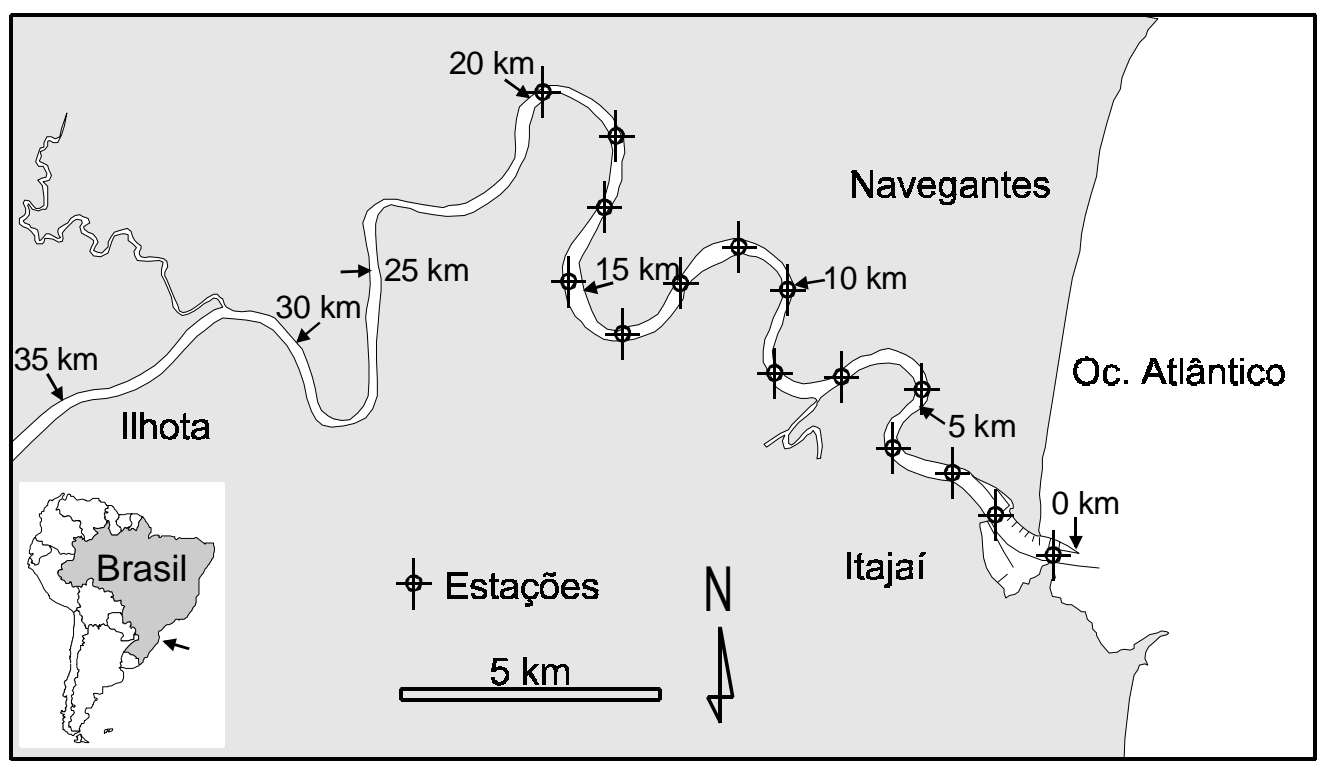

Figura 1 - Localização do estuário do rio Itajaí-Açu, com o posicionamento das estações amostrais. 
salinidade atua como indicador de massa de água. Contudo, em estuários que apresentam uma cunha salina com presença de massa de água costeira de mistura, torna-se interessante também estimar o tempo de renovação da água da cunha salina em si. O objetivo deste trabalho é avaliar o balanço de sal no estuário do rio Itajaí-Açu aplicando o teorema hidrográfico de Knudsen (Dyer, 1997) e, através das inferências das taxas de fluxo entre os compartimentos, estimar o tempo de transito no estuário.

\section{MATERIAIS E MÉTODOS}

\section{Dados de Campo}

Os dados de campo utilizado neste trabalho foram obtidos durante o projeto "Transport and Transformation Processes in the Itajaí-Açu Estuary" - TRANSIT (Univali-UniKiel, MCT Mar41). Os dados de distribuição de salinidade utilizados foram coletados através de um experimento de quinze dias, quando foram realizados dois levantamentos diarios, um na baixamar e outro na preamar, do dia 7 até
21 de janeiro de 2000. Estes levantamentos foram realizados com uma embarcação rápida, e as estações de coleta foram efetuadas a cada 1,5 quilômetros, a partir da desembocadura até um pouco a montante da última observação de salinidade. Cada levantamento foi realizado em um intervalo de mais ou menos 1 hora, garantindo assim uma visão sinóptica da distribuição das propriedades. Em cada estação, utilizou-se uma sonda ME-Grisard ${ }^{\mathrm{TM}}$ modelo EcoProbe $\AA$, a qual transmitia informações de profundidade, salinidade, temperatura e turbidez, em tempo real, para um computador a bordo (Zaleski et al., 2001; Schettini et al., 2002).

As informações coletados foram posteriormente reduzidas através de rotinas em ambiente Matlab ${ }^{\circledR}$ (MathWorks Inc. ${ }^{\mathrm{TM}}$ ), fornecendo valores espaçados regularmente na vertical com resolução de $0,25 \mathrm{~m}$. A partir dos dados reduzidos foram gerados gráficos de distribuição da salinidade com o programa Surfer® (Golden Software ${ }^{\mathrm{TM}}$ ), como mostrado na Figura 2. Para quantificação do grau de mistura no estuário, foi considerada como zona de mistura a distância entre a desembocadura

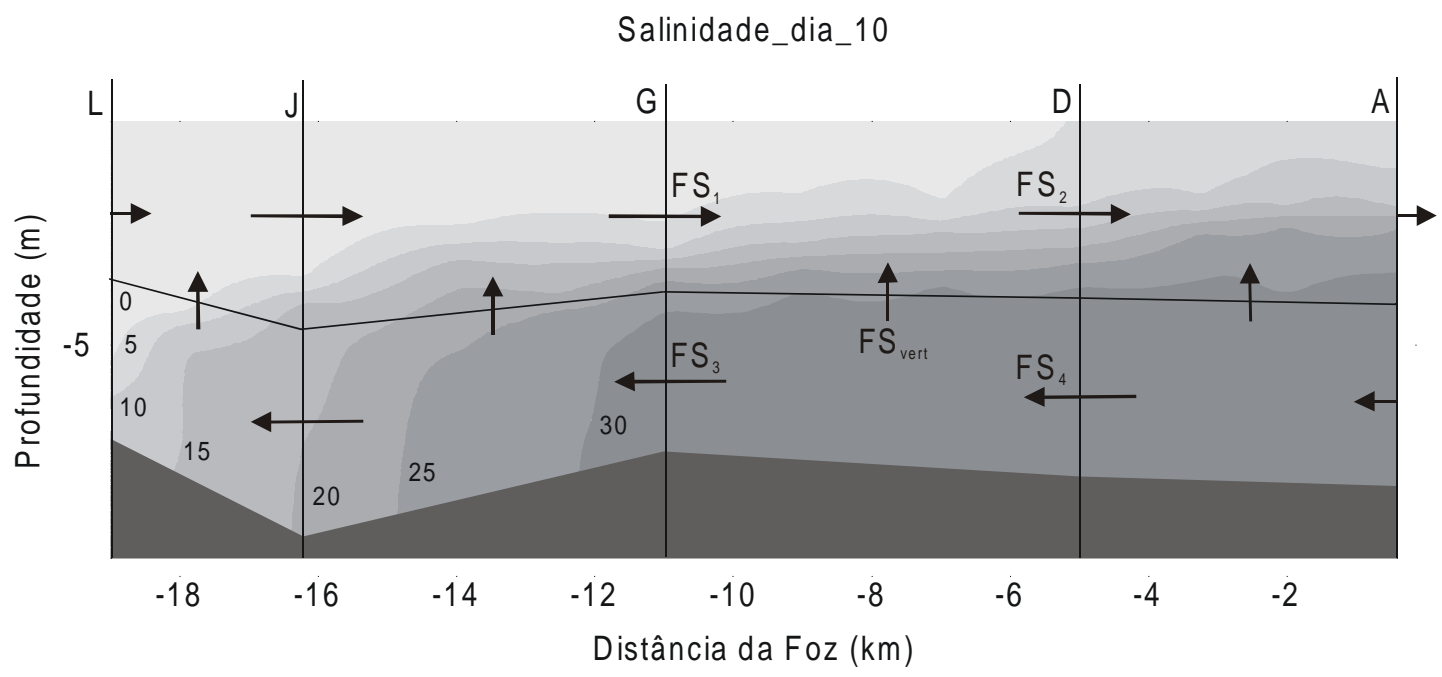

Figura 2 - Perfil de salinidade (psu) do estuário do rio Itajaí-Açu, mostrando a divisão das caixas (AD, DG, GJ, JL) para a aplicação modelo de caixas baseado no teorema hidrográfico de Knudsen. FS, representam os fluxos de sal estimados, em $\mathrm{kg} \mathrm{m}^{-2} \mathrm{~s}^{-1}$, que serão apresentados na Tabela 1. 
até onde a isohalina de 2 interceptava o fundo. A área compreendida entre a isohalina de 2 até a superfície foi definida como água fluvial, entre as isohalinas 2 e 30 como água de mistura, e entre a isohalina de 30 e o fundo, água marinha. Para comparar as diferenças no grau de mistura entre as situações de sizígia e quadratura foi definida uma razão de mistura dada pela razão entre o volume de água fluvial $(F)$ e da água de mistura (M). Assim, quanto menor a razão F/ $M$, maior o grau de mistura de água no estuário.

Os dados de descarga fluvial utilizados foram obtidos através da ANEEL, "Agência Nacional de Energia Elétrica" - Estação Fluviométrica de Indaial, que oferece dados de nível da água e vazão do rio Itajaí-açu de hora em hora via Internet (http://www.aneel.gov.br/). A estação fluviométrica de Indaial está situada a $90 \mathrm{~km}$ da desembocadura do estuário, e recebe o aporte de $11.110 \mathrm{~km}^{2}$, ou em torno de $70 \%$ de toda a bacia. Esta é a estação fluviométrica mais a jusante da bacia sem influência de maré.

Os dados de batimetria da desembocadura até $12 \mathrm{~km}$ a montante do baixo estuário foram cedidos pela empresa de dragagem Ballast-HAM. A batimetria entre 12 $\mathrm{km}$ e $35 \mathrm{~km}$ a montante da foz foi realizada em maio de 2002 com um eco-batimetro Honeywell-Elac ${ }^{\mathrm{TM}}$ com linhas transversais espaçadas em intervalos de 200 metros, com posicionamento através de receptor de posicionamento global marca Garmin ${ }^{\mathrm{TM}}$ modelo XL12®.

\section{Modelo de Caixa}

Para avaliar o balanço salino no estuário do Rio Itajaí-açu foi empregado um modelo de caixa baseado no teorema hidrográfico de Knudsen (Dyer, 1997). Este modelo é apropriado para estuários altamente estratificados, como é o caso do estuário do rio Itajaí-açu. O modelo consiste em subdividir o estuário em um dado numero de seções, denominado caixas (Figura 2), com dimensões escolhidas arbitrariamente, contudo de acordo com a resolução dos dados disponíveis (Sheldon \& Alber, 2002). Cada caixa desta foi subdividida em duas camadas homogêneas com direções de fluxo contrárias, uma na parte inferior, com salinidade alta, e outra na parte superior com salinidade baixa (Figura 3). A caixa mais interior no estuário corresponde à máxima intrusão da cunha salina, permitindo somente a entrada de água fluvial pela camada superior, enquanto que pela ultima seção da camada inferior não ocorre entrada de água salina.

Miranda et al. (2002), assumindo a conservação de volume e sal para uma dada caixa define:

$$
\begin{aligned}
& -u_{1} A_{1}+u_{3} A_{3}=-Q_{f} \\
& u_{2} A_{2}-u_{4} A_{4}=Q_{f} \\
& -u_{1} A_{1}+u_{3} A_{3}+u_{2} A_{2}-u_{4} A_{4}=0
\end{aligned}
$$

e

$-S_{1} u_{1} A_{1}+S_{3} u_{3} A_{3}+S_{2} u_{2} A_{2}-S_{4} u_{4} A_{4}=0$

sendo $A_{i}$ as áreas das camadas das seções transversais, $u_{i}$ e $S_{i}$ as respectivas velocidades e salinidades para cada seção. Respeitando a conservação de massa, o transporte de sal resultante através das seções transversais deve ser nulo e, a partir da equação (4), seguem as seguintes igualdades:

$$
\begin{aligned}
& S_{1} u_{1} A_{1}=S_{3} u_{3} A_{3} \\
& S_{2} u_{2} A_{2}=S_{4} u_{4} A_{4}
\end{aligned}
$$

As Equações 1, 2, 5 e 6 constituem um sistema de quatro equações com quatro incógnitas, $u_{1}, u_{2}, u_{3}, u_{4}$, cuja solução é:

$$
\begin{aligned}
& u_{1}=Q_{f} / A_{1}\left(1-\left(S_{1} / S_{3}\right)\right), \\
& u_{2}=Q_{f} / A_{2}\left(1-\left(S_{2} / S_{4}\right)\right), \\
& u_{3}=Q_{f} / A_{3}\left(\left(S_{3} / S_{1}\right)-1\right),
\end{aligned}
$$


e

$\mathrm{u}_{4}=\mathrm{Q}_{\mathrm{f}} / \mathrm{A}_{4}\left(\left(\mathrm{~S}_{4} / \mathrm{S}_{2}\right)-1\right)$

O fluxo vertical ascendente de volume pode ser estimado pela diferença entre os transporte na camada de fundo, ou seja, $\mathrm{u}_{4} \mathrm{~A}_{4}$ $u_{3} A_{3}$. E dividindo este fluxo vertical médio pela área superficial da caixa chegamos à velocidade vertical média, $\overline{\mathrm{W}}$.

Para se encontrar o fluxo de sal médio, em $\mathrm{kg} \cdot \mathrm{m}^{-2} \cdot \mathrm{s}^{-1}$, em cada seção do estuário, ou em cada uma das caixas do modelo, multiplicase a concentração de sal média de cada caixa pelas velocidades estimadas, $u_{i}$ da mesma caixa. Neste sentido, assume-se a simples conversibilidade da salinidade obtida em PSU em kg. $\mathrm{m}^{-3}$, ou seja, assume-se uma densidade da água igual a 1.

Para se aplicar o modelo, foi feita uma média entre os perfis de salinidade das campanhas de preamar e baixamar, o que forneceu um perfil de transporte residual, ou seja, sem a interferência da variação de nível de maré. Devido a um forte aumento na descarga fluvial ocorrida no dia 15 de janeiro, foi utilizado somente os sete primeiros dias de dados para se aplicar o teorema hidrográfico de Knudsen. Nestes primeiros dias a descarga fluvial oscilou entre 170 e $240 \mathrm{~m}^{3} \cdot \mathrm{s}^{-1}$, condições estas que permitem que a cunha salina avance entre 15 e $20 \mathrm{~km}$ a montante da desembocadura.

\section{RESULTADOS E DISCUSSÃO}

\section{Balanço de Sal}

O experimento iniciou-se em condições de maré sizígia, com as maiores variações observadas nos dias 7, 8 e 9 de janeiro. Nos dias 10, 11, 12 e 13 de janeiro as condições foram de maré de quadratura (Figura 4). A velocidade vertical média obtida (Figura 5), bem como o fluxo vertical médio de sal apresentou variabilidade com as diferentes situações de maré. Nos três primeiros dias, em condições de sizígia, os maiores fluxos verticais de sal, da ordem de $3,6 \times 10^{-3} \mathrm{~kg} \cdot \mathrm{m}^{-2} \cdot \mathrm{s}^{-1}$, foram encontrados na caixa mais próxima à foz, caixa um (Tabela 1). No dia 10, já em condição de

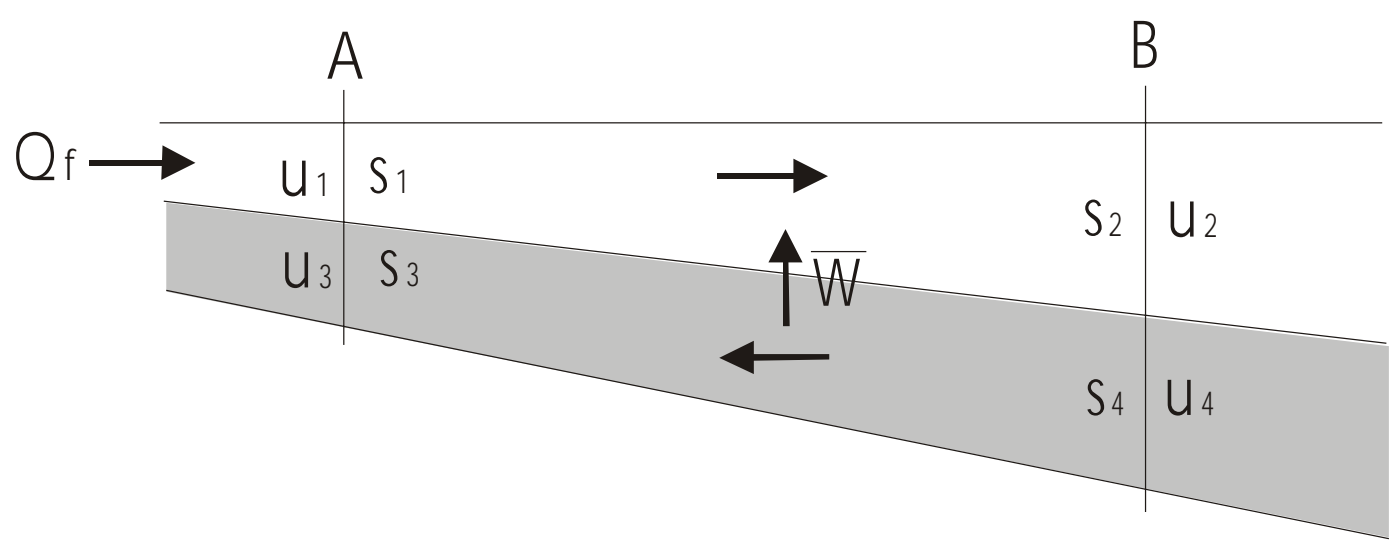

Figura 3 - Diagrama esquemático dos transportes de volume e sal através das seções transversais $A$ e $B$ de um canal estuarino. Os índices 1-2 e 3-4 indicam propriedades das camadas, superior e inferior respectivamente. S é a salinidade em "psu", u é velocidade horizontal em " $\mathrm{m}^{2} \mathrm{~s}^{-1}$ ", W é a velocidade vertical média em " $\mathrm{m}^{2} \mathrm{~s}^{-1}$ " e $\mathrm{Q}_{\mathrm{f}}$ a descarga fluvial em " $\mathrm{m}^{3} \mathrm{~s}^{-1}$ ". Segundo Defant, 1961 apud Miranda et al 2002. 


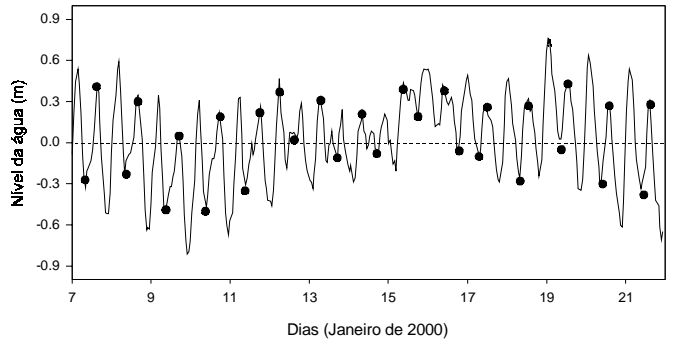

Figura 4 - Variação do nível do mar durante o período do experimento. Os círculos negros indicam os instantes em que foram realizados os levantamentos de variáveis físicas no estuário.

quadratura, observou-se uma mudança neste padrão, onde a caixa mais próxima à foz continuou com o mesmo fluxo médio observado nos três primeiros dias, porém o fluxo máximo foi observado na terceira caixa, $5 \times 10^{-3} \mathrm{~kg} \cdot \mathrm{m}^{-}$ ${ }^{2} . \mathrm{s}^{-1}$, voltando a diminuir para montante. No dia 11 verificou-se um padrão similar ao ocorrido nos três primeiros dias, com o maior fluxo vertical de sal ocorrendo na caixa mais próxima à foz. O fluxo vertical de sal nesta caixa diminuiu para aproximadamente $1,5 \times 10^{-3} \mathrm{~kg} \cdot \mathrm{m}^{-2} \cdot \mathrm{s}^{-1}$ nos dois últimos dias, quando novamente os maiores fluxos voltaram a ocorrer na segunda caixa, à $7 \mathrm{~km}$ da foz, tal como fora observado no dia 10 de janeiro.

O comportamento do fluxo vertical de sal expressa os padrões de mistura que ocorrem no estuário. A razão F/M média encontrada para os três primeiros dias, em condição de sizígia, foi de 0,24 , enquanto que para os três últimos dias em condição de quadratura a razão aumentou para 0,61 . Este resultado permite afirmar que, para o período em questão, quando predominou condições de baixa descarga fluvial, o estuário apresentou maior grau de mistura em situações de maior amplitude de maré. $\mathrm{O}$ mesmo resultado foi verificado quando comparamos as médias das velocidades verticais nos três primeiros e três últimos dias. Nos três primeiros dias o valor de velocidade vertical média $=2,06 \times 10^{-4} \mathrm{~m} . \mathrm{s}^{-1}$, enquanto

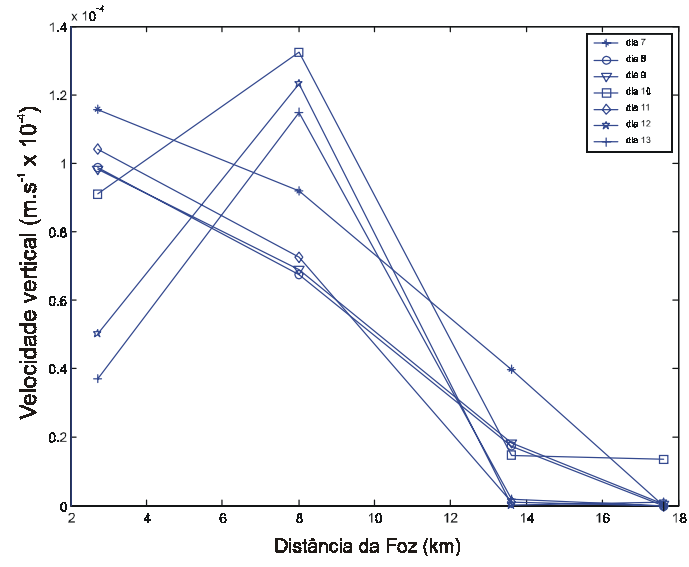

Figura 5 - Variação das velocidades verticais (W) ao longo do estuário do rio Itajaí-Açu entre os dias 7 e $13 / 01 / 2000$

que para a situação de quadratura esta decaiu para $=1,69 \times 10^{-4} \mathrm{~m} \cdot \mathrm{s}^{-1}$. Estes valores demonstram a relação entre mistura e fluxo vertical de sal neste estuário tipo cunha salina modulados pela variação das condições de maré.

Os processos de transporte em estuários altamente estratificados são governados principalmente pela advecção fluvial, tendo os processos associados às oscilações de marés um papel secundário (Dyer, 1997). Os processos de mistura ocorrem principalmente pelo mecanismo de intrusão de massa, onde a massa é transferida da camada inferior, menos turbulenta, para a superior. Este processo é gerado pela fricção interfacial do escoamento fluvial sobre a água marinha. Outro processo gerador de mistura é a turbulência, a qual é gerada pela dissipação de energia da onda de maré à medida que esta adentra no corpo estuarino, e será tão maior quanto maior for a altura de maré. Os resultados encontrados indicam que em condições de baixa descarga do rio Itajaí-Açu, a modulação sinodical da altura da maré em períodos de sizígia e quadratura altera os processos hidrodinâmicos no estuário. 
Tabela 1 - Fluxos advectivos de sal $\left(\mathrm{FS}_{1}, \mathrm{FS}_{2}, \mathrm{FS}_{3}, \mathrm{FS}_{4}\right)$ e fluxos verticais de sal $\left(\mathrm{FS}_{\text {vert }}\right)$, em kg m $\mathrm{m}^{-2} \mathrm{~s}^{-1}$, nas seções transversais do estuário. As caixas estâo na unidade de quilômetros de distância da barra.

\begin{tabular}{c|cccccc}
\hline Dia & Caixas & $\mathrm{FS}_{1}$ & $\mathrm{FS}_{2}$ & $\mathrm{FS}_{3}$ & $\mathrm{FS}_{4}$ & $\mathrm{FS}_{\text {vert }}$ \\
\hline 7 & $0.4-5.0$ & 4.25 & 8.55 & 9.57 & 7.86 & $3.6 \times 10^{-3}$ \\
& $5.0-11.0$ & 1.46 & 4.25 & 3.55 & 9.57 & $2.4 \times 10^{-3}$ \\
& $11.0-16.2$ & 0.35 & 1.46 & 0.54 & 3.55 & $7.1 \times 10^{-4}$ \\
\hline 8 & $0.4-5.0$ & 2.76 & 6.07 & 6.22 & 5.58 & $3.1 \times 10^{-3}$ \\
& $5.0-11.0$ & 0.80 & 2.76 & 1.94 & 6.22 & $1.9 \times 10^{-3}$ \\
& $11.0-16.2$ & 0.16 & 0.80 & 0.24 & 1.94 & $2.9 \times 10^{-4}$ \\
\hline 9 & $0.4-5.0$ & 4.05 & 8.60 & 9.12 & 7.91 & $4.3 \times 10^{-3}$ \\
& $5.0-11.0$ & 1.19 & 4.05 & 2.89 & 9.12 & $2.7 \times 10^{-3}$ \\
& $11.0-16.2$ & 0.35 & 1.19 & 0.53 & 2.89 & $4.7 \times 10^{-4}$ \\
& $16.2-19.0$ & 0.05 & 0.35 & 0.06 & 0.53 & $3.9 \times 10^{-6}$ \\
\hline 10 & $0.4-5.0$ & 7.11 & 12.16 & 16.01 & 11.18 & $4.2 \times 10^{-3}$ \\
& $5.0-11.0$ & 1.52 & 7.11 & 3.70 & 16.01 & $5.6 \times 10^{-3}$ \\
& $11.0-16.2$ & 0.63 & 1.52 & 0.97 & 3.70 & $4.4 \times 10^{-4}$ \\
& $16.2-19.0$ & 0.04 & 0.63 & 0.05 & 0.97 & $1.6 \times 10^{-4}$ \\
\hline 11 & $0.4-5.0$ & 3.02 & 6.74 & 6.80 & 6.20 & $3.2 \times 10^{-3}$ \\
& $5.0-11.0$ & 0.80 & 3.02 & 1.95 & 6.80 & $1.7 \times 10^{-3}$ \\
& $11.0-16.2$ & 0.51 & 0.80 & 0.78 & 1.95 & $1.6 \times 10^{-5}$ \\
\hline 12 & $0.4-5.0$ & 3.94 & 6.36 & 8.87 & 5.84 & $1.7 \times 10^{-3}$ \\
& $5.0-11.0$ & 0.37 & 3.94 & 0.91 & 8.89 & $3.4 \times 10^{-3}$ \\
& $11.0-14.0$ & 0.28 & 0.37 & 0.75 & 0.91 & $5.6 \times 10^{-6}$ \\
& $14.0-16.2$ & 0.06 & 0.28 & 0.09 & 0.75 & $1.3 \times 10^{-5}$ \\
\hline 13 & $0.4-5.0$ & 4.19 & 6.45 & 9.44 & 5.93 & $1.5 \times 10^{-3}$ \\
& $5.0-11.0$ & 0.18 & 4.19 & 0.44 & 9.44 & $3.9 \times 10^{-3}$ \\
& $11.0-15.1$ & 0.10 & 0.18 & 0.16 & 0.44 & $4.6 \times 10^{-5}$ \\
\hline
\end{tabular}

\section{Tempo de Trânsito}

Tempo de trânsito é definido como sendo o tempo necessário para que uma substância ou partícula percorra uma distância pré-definida. Em um estuário pode-se distinguir o tempo de trânsito da água fluvial e água salgada, no qual que para o primeiro, será o tempo gasto por uma parcela d'água desde que esta entre pela cabeceira do estuário até sua saída na desembocadura. Contudo, para a água marinha a situação torna-se um pouco mais complexa devido ao fato de que a água marinha entra e sai do estuário através da desembocadura. Em função dos processos de circulação estuarina, forma-se uma corrente para montante para compensar a perda de volume causado pelo intrusionamento de massa para a camada superior. Além do volume perdido pelo intrusionamento, a camada logo abaixo da interface também sofre os efeitos friccionais em que momentum é transferido de cima para baixo, carreando também uma parcela de água salina para jusante.

Eliminando os efeitos causados pela oscilação da maré, através do uso da promediação dos parâmetros medidos entre os levantamentos de preamar e baixamar, e a 
aplicação do princípio de conservação de volume e sal, o modelo de caixa permite estimar o tempo necessário à completa renovação do volume estuarino. Para isto, conhecendo as velocidades médias, $u_{i}$, em cada uma das caixas e suas respectivas áreas transversais, obtêm-se os fluxos de massa médios $Q_{i}$ entre as caixas, bem como o fluxo vertical (Figura 3). O tempo de trânsito é calculado para cada caixa e para as duas camadas de cada caixa separadamente. Sendo assim, depois de obtidos todos os fluxos para cada uma das caixas e seus respectivos volumes, o tempo de trânsito é calculado como:

$$
\mathrm{T} t_{\text {sup }}=\mathrm{V}_{\text {sup }} / \mathrm{Q}_{2} \quad \text { e } \quad \mathrm{T} t_{\text {inf }}=\mathrm{V}_{\text {inf }} / \mathrm{Q}_{4}
$$

onde $\mathrm{V}_{\text {sup }}$ e $\mathrm{V}_{\text {inf }}$ são os volumes das camadas, superior e inferior, respectivamente. $Q_{2}$ é o fluxo que sai da camada superior $\mathrm{Q}_{4}$ é o fluxo que entra na camada inferior.

O tempo de trânsito da água fluvial no estuário foi obtido através da soma dos tempos estimados, para as camadas superiores, de cada uma das caixas. A soma se restringe as camadas superiores, visto que a parcela de água fluvial, menos densa, flui por sobre a água marinha, mais densa. Esta é a principal característica dos estuários altamente estratificados, como é o caso do estuário do rio Itajaí-Açu. Em outras palavras, tempo de trânsito da água fluvial é o tempo gasto por uma parcela de água fluvial para percorrer toda a extensão do estuário, desde sua cabeça até a foz do rio.

O tempo de trânsito foi estimado para os sete dias, compreendendo situações de

Tabela 2 - Tempo de trânsitos das águas fluvial e marinha no estuário do rio Itajaí-açu.

\begin{tabular}{c|ccc}
\hline \hline DIA & $\begin{array}{c}\text { DESCARGA } \\
\left(\mathrm{m}^{3} \cdot \mathrm{s}^{-1}\right)\end{array}$ & $\begin{array}{c}\text { Tt ÁGUA FLUVIAL } \\
\text { (Horas) }\end{array}$ & $\begin{array}{c}\text { Tt AGUA MARINHA } \\
\text { (Horas) }\end{array}$ \\
\hline 7 & 151 & 14.2 & 34.2 \\
8 & 116 & 20 & 50.1 \\
9 & 170 & 17.1 & 62.5 \\
10 & 241 & 11.9 & 44.1 \\
11 & 262 & 10.6 & 38.4 \\
12 & 265 & 9.4 & 41.2 \\
13 & 300 & 9.2 & 84.2 \\
\hline média & 215 & 13.2 & 50.7 \\
\hline \hline
\end{tabular}

baixa a média descarga fluvial (Tabela 2). No dia 7, com uma descarga média de $151 \mathrm{~m}^{3} . \mathrm{s}^{-1}$ , o tempo de trânsito estimado foi de 14.2 horas para a água fluvial e 34.2 horas para a água marinha. No dia seguinte, dia 8, houve uma leve diminuição na descarga fluvial, o que acarretou em um pequeno aumento no tempo de transito das águas fluvial e marinha no estuário. Com uma descarga de $116 \mathrm{~m}^{3} \cdot \mathrm{s}^{-1}$, o tempo de transito foi de 20 horas para a água fluvial e 50.1 horas para a água marinha. A descarga no dia 9 voltou a subir, agora para $170 \mathrm{~m}^{3} \cdot \mathrm{s}^{-1}, \mathrm{o}$ que fez com que o tempo de trânsito da água fluvial caísse para 17.1 horas. A água marinha, ao contrário do que era esperado, apresentou valores de tempo de trânsito maiores com o aumento da descarga fluvial, foi de 50.1 para 62.5 horas. Nos dias seguintes, o tempo de trânsito da água fluvial apresentou uma relação inversa a descarga fluvial, porém o tempo de trânsito da água marinha não mostrou a mesma relação. Contudo, ao se analisar as médias dos tempos de trânsito podemos verificar que para uma descarga média de $215 \mathrm{~m}^{3} . \mathrm{s}^{-1}$ o tempo de trânsito médio da água fluvial foi de 13.2 horas, enquanto que para a água marinha foi de 50.7 horas. Com isto verificamos que para uma descarga média, cerca de $215 \mathrm{~m}^{3} \cdot \mathrm{s}^{-1}$, o tempo de trânsito estimado para a água marinha foi 3 vezes maior do que o da água fluvial.

Embora o modelo de caixas de Knudsen seja apropriado para estuários altamente estratificados, suas estimativas de tempo de trânsito representam valores subestimados (Tomczak, 2000), visto que este superestima os valores de velocidades $u_{i}$ (Figura 3). Valores de tempo de trânsito, bem como tempo de residência, são tidos como importantes ferramentas no gerenciamento de ambientes estuarinos, porém é importante que se conheça as limitações do modelo e de seus resultados. No presente caso, observou-se que a maré influencia grandemente os padrões de mistura e transporte ao longo do ciclo sizígia e quadratura, demonstrando que os processos de difusão turbulenta também devem ser considerados. 


\section{FONTES DE IMPRECISÃO}

A determinação do tempo de trânsito em estuários baseia-se em medições e estimativas, havendo certo grau de incertezas em vários dos parâmetros utilizados. Estas imprecisões podem ser significativas ou desprezíveis em função de sua importância. Pilson (1985), ressalta a importância de se conhecer as fontes de imprecisão em trabalhos desta natureza, visto que isto possibilita dimensionar o nível de erro associado às estimativas obtidas.

Volume: Foi desprezada qualquer irregularidade do canal entre os perfis escolhidos como limite da caixa. Outro fator a ser levado em consideração é a variação de maré. Embora o estuário do rio Itajaí-açú esteja localizado em uma região de micro-marés a variação do nível de água causa certa imprecisão no valor calculado de volume do estuário, e este será tanto maior nos períodos de sizígia do que em quadratura.

Descarga Fluvial: como os dados utilizados nesta estimativa do tempo de trânsito no estuário do Rio Itajaí-açú não foram coletados especificamente para se aplicar o modelo de caixas, logo, não foram coletadas informações de correntes para se calcular a descarga na cabeça do estuário. Os valores de descarga fluvial utilizados foram conseguidos junto a uma estação linimétrica localizada a uma distância de aproximadamente $80 \mathrm{~km}$ do estuário. Deste modo, se transportados para o estuário, os valores de descarga fluvial representam valores subestimados.

Salinidade: no presente caso, a informação da distribuição de salinidade é o menor fator de incerteza, contudo cabe ressaltar que os perfis de salinidade utilizados consistiram em perfis quase sinópticos. Um fator importante de imprecisão nas estimativas relaciona a salinidade com os valores de descarga fluvial utilizados. Como a mobilidade da cunha salina neste estuário está cerca de 70\% relacionada com a descarga fluvial (Schettini \& Truccolo, 1999), e como os dados de descarga fluvial apresentam uma defasagem do ponto de medição até o estuário, uma incongruência entre o perfil de salinidade utilizado e a descarga fluvial possivelmente gerou alguma imprecisão.

Dimensões das caixas: o modelo de caixas clássico, segundo Officer (1980, apud Sheldon \& Alber, 2002), prevê a escolha arbitrária dos limites das caixas. Porém, isto pode implicar em erros nos fluxos calculados e resultar numa imprecisão na lei de conservação de massa. Para minimizar estes erros, Miller \& McPherson (1991, apud Sheldon \& Alber, 2002), propuseram um método para calcular os limites ótimos para as caixas, baseado na razão entre o fluxo de massa através da caixa e seu volume. Eles recomendam uma razão ótima em torno de 0,2 a 0,5. Estudos mais específicos que venham a rever estes parâmetros, como tempo de trânsito ou balanço salino, devem levar em consideração todos estes métodos de minimização da imprecisão para que se possa chegar a valores precisos.

\section{CONCLUSÕES}

Através dos valores obtidos de velocidades verticais, corroborados pelos valores da razão $F / M$, as situações de maré de sizígia apresentaram um maior grau de mistura de águas neste estuário. Os tempos de trânsito estimados nos mostram que a água marinha leva três vezes mais tempo para percorrer o estuário do que a água fluvial. Os valores obtidos, em condições de descarga fluvial média, sugerem um tempo de trânsito para a água fluvial da ordem de 13,2 horas, e 50,7 horas para a água marinha. Contudo, ressalta-se aqui que o presente estudo têm caráter preliminar, dado que as estimativas não contaram com informações importantes como a velocidade de corrente. 
O clássico modelo de caixas, baseado no teorema hidrográfico de Knudsen, apesar de possuir varias características que restringem seu uso, ainda possui uma grande utilidade, visto que sua aplicação requer um pequeno numero de parâmetros, como perfil de salinidade, volume do estuário e fluxo de água fluvial. Os valores obtidos de balanço salino e tempo de transito neste trabalho, consistem em informações de estado estático e não devem ser entendidos como sendo médias para o estuário. Para se obter valores médios para o estuário, estudos específicos devem ser realizados, com campanhas de campo objetivando adquirir todos os dados necessários à aplicação deste modelo.

\section{REFERÊNCIAS BIBLIOGRÁFICAS}

Bordalo, A.A. \& M.E.C. Vieira. 2000. The Douro estuary (Portugal) a mesotidal salt wedge. In: Oceanologica Acta. Vol. 23 n. 5. p. 585594.

Cameron, W.M. \& D.W. Pritchard. 1963. Estuaries. p. 306-332. In: Hill, M.N. (Ed.) The sea. New York, Wiley Interscience.

Dyer, K.R. 1997. Estuaries: a physical introduction. 2nd ed., New York, John Wiley and Sons. 195p.

Miranda, L. B. de, Castro, B. M. de \& B. Kjerfve. 2002. Princípios de oceanografia física de estuários. 1ed. São Paulo, Editora da Universidade de São Paulo, 416p.

Pilson, M.E.Q. 1985. On the residence time of water in Narragansett Bay. Estuaries. Vol. 8. n. 1. p. 2-14.

Schettini, C.A.F. 2002. Caracterização física do estuário do rio Itajaí-Açu. Revista Brasileira de Recursos Hídricos, 7(1):123142.
Schettini, C.A.F., Kjerfve, B. \& J.L.B. Carvalho. 1997. Dispersão e transporte de sal no estuário do rio Itajaí-açu em condições de baixa descarga. In: Congresso Latinoamericano Sobre Ciências do Mar, 7, Santos, Resumos Expandidos. Vol. 2, ALICMAR/IOUSP, p. 424-425.

Schettini, C.A.F., Ricklefs, K., Zaleski, A.R. \& S. Brandt. 2002. The role of the tide on the salt wedge displacement and mixing in the Itajaí estuary, southern Brazil. In: Burchard, H., Gardeike, B., Grabemann, I., Kappenberg, J. (Eds.) 11th International Biennal Conference on Physics of Estuaries and Coastal Seas: Extended Abstracts. Germany. Hamburg, p. 9-12.

Schettini, C.A.F. \& E.C. Truccolo. 1999. Dinâmica da intrusão salina no estuário do rio Itajaí-açu. In: Congresso Latinoamericano Sobre Ciências do Mar, 8, Trujillo, Resumenes ampliados. Tomo II, UNT/ALICMAR, p. 639-640.

Sheldon, J.E \& M. Alber. 2002. A comparison of the residence time calculations using simple compartment models of the Altamaha river estuary, Georgia. Estuaries. Vol. 25, n. 6b. p. 1304-1317.

Tomczak, M. 2000. Coastal and shelf oceanography. cap. 15. Disponível em: <http://www.lei.furg.br/ocfis/mattom/ ShelfCoast/chapter15.html>. Acesso em: 4 fev. 2002.

Zaleski, A.R., Schettini, C. A. F., Ricklefs, K. \& S. Brandt. 2001. Avaliação dos padrões de mistura no estuário do rio Itajaí-açu em freqüência diária. In: Semana Nacional de Oceanografia, 14, 2001, Rio Grande. Anais. Rio Grande: FURG, CD ROM. 